\title{
Microstructure Modifications and Associated Corrosion Improvements in GH4169 Superalloy Treated by High Current Pulsed Electron Beam
}

\author{
Yichang Su, 1,2 Guangyu Li, ${ }^{1}$ Liyuan Niu, ${ }^{2}$ Shengzhi Yang, ${ }^{3}$ Jie Cai, $^{3}$ and Qingfeng Guan ${ }^{3}$ \\ ${ }^{1}$ The Key Lab of Automobile Materials, Ministry of Education, College of Materials Science and Engineering, Jilin University, \\ Nanling Campus, Changchun 130025, China \\ ${ }^{2}$ Zhejiang Industry and Trade Vocational College, Wenzhou 325003, China \\ ${ }^{3}$ School of Materials Science and Engineering, Jiangsu University, Zhenjiang 212013, China
}

Correspondence should be addressed to Qingfeng Guan; guanqf@ujs.edu.cn

Received 20 November 2014; Accepted 8 February 2015

Academic Editor: Gang Ji

Copyright (C) 2015 Yichang Su et al. This is an open access article distributed under the Creative Commons Attribution License, which permits unrestricted use, distribution, and reproduction in any medium, provided the original work is properly cited.

\begin{abstract}
The surface of the nickel-based superalloy GH4169 was subjected to high-current pulsed electron beam (HCPEB) treatment. The microstructural morphologies of the material were analysed by means of optical microscope (OP), scanning electron microscope (SEM), and transmission electron microscope (TEM). The results reveal that the irradiated surface was remelted and many craters were formed. The density of craters decreased with the increment of HCPEB pulses. After 20-pulsed HCPEB irradiation, nanostructures were formed in the melted region of the surface. Furthermore, slipping bands and high density of dislocations were also formed due to the severe plastic deformation. The selective purification effect, homogenized composition, nanostructures, and dislocation slips introduced by HCPEB irradiation bring a significant improvement of corrosion resistance of GH4169 superalloy.
\end{abstract}

\section{Introduction}

Recently, high-current pulsed electron beam (HCPEB) has proved to be a powerful tool for surface modification of metallic materials [1-4]. During the process of HCPEB irradiation, a high energy $\left(10^{8}-10^{9} \mathrm{~W} / \mathrm{cm}^{2}\right)$ is instantly deposited in a thin layer (less than tens of micrometers) within a short time (a few microseconds). Depending on the temperature reached at the surface of the material, different physical processes, such as extremely fast heating, melting, and cooling can be successively involved. Simultaneously, the dynamic stress fields induced in these processed can cause high rate deformation. As a consequence, abundant substantial modification of surface characteristics, such as ultrafine grain [5], nanostructures [1], and complex crystal defects [6] can be obtained within the irradiated surface layer, which will remarkably influence the physical mechanical properties of the irradiated surface.

Nickel-based superalloy GH4169 (Inconel 718) was initially developed for the use as a structural material in aircraft gas turbine engines for the aerospace industry, but it is now extensively used in the oil and gas industry for a variety of applications due to its excellent mechanical properties, superior high temperature properties, and good corrosion resistance up to $650^{\circ} \mathrm{C}$ [7-9]. As we know, due to the severe corrosion environments and the existence of large amount of chlorides in the drilling mud, it brings forward a high request to improve the corrosion resistance of metallic materials. Many researchers have recently conducted a great deal of research regarding HCPEB-treated metallic materials, such as AZ91 magnesium alloy [10], WCCo hard alloy [11], 316L Stainless Steel [12], and MCrAlY metallic coating [5]. The corrosion resistance of material surfaces is enhanced after the HCPEB treatment, and the structure of treated surface is refined. In the present work, superalloy GH4169 treated with HCPEB irradiation is reported. The microstructural formation mechanism, especially the surface nanocrystallization, and the associated corrosion properties are investigated. 
TABLE 1: Chemical composition of superalloy GH4169 (wt \%).

\begin{tabular}{cccccccccc}
\hline Element & $\mathrm{Ni}$ & $\mathrm{Cr}$ & $\mathrm{Fe}$ & $\mathrm{Nb}+\mathrm{Ta}$ & $\mathrm{Mo}$ & $\mathrm{Ti}$ & $\mathrm{Co}$ & $\mathrm{Al}$ & $\mathrm{Si}$ \\
\hline Content & 51.55 & 19.62 & $\mathrm{Bal}$ & 5.08 & 3.03 & 1.08 & $<1.0$ & 0.58 & 0.17 \\
\hline
\end{tabular}

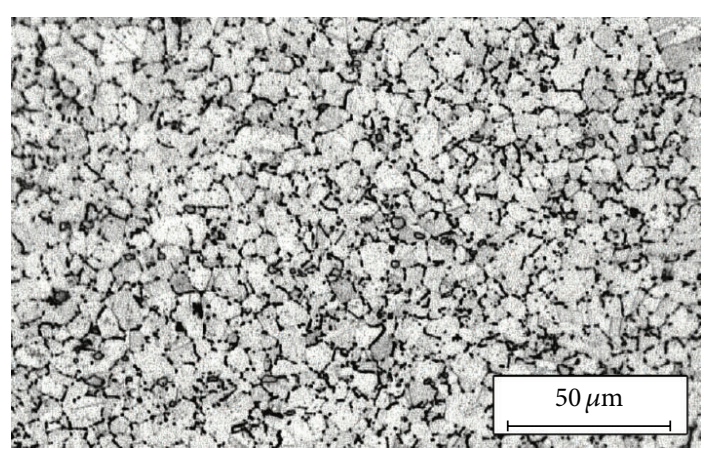

FIGURE 1: Metallographic image of the initial microstructure of superalloy GH4169.

\section{Experimental}

2.1. HCPEB Treatment. Ni-based superalloy GH4169 used as the target material was cut into square-shaped samples of approximately $10 \times 10 \times 10 \mathrm{~mm}$. The nominal chemical composition is listed in Table 1. The initial microstructure of the superalloy GH4169 has a grain size of about $4 \sim 10 \mu \mathrm{m}$ (shown in Figure 1).

Before HCPEB irradiation, one side of the surface was prepared by mechanical polishing to ensure a similar initial surface state. Then the samples were irradiated at room temperature with 1,10 , and 20 pulses using a Nadezhda- 2 type HCPEB source. The HCPEB bombardments were carried out under the following parameters: the electron energy $27 \mathrm{keV}$, the current pulse duration $1.5 \mu \mathrm{s}$, the energy density $4 \mathrm{~J} / \mathrm{cm}^{2}$, and the vacuum $10^{-5}$ torr. More details about the principle of the HCPEB system are in [4].

2.2. Characterization. Surface microstructure of the samples was performed by using optical microscope (OP) of type LEICA DM-2500M and scanning electron microscope (SEM) of type JSM-7100F. Microstructures were further examined with a transmission electron microscope (TEM) of type JEM2100. The foils used for TEM observations were obtained by preparing one-sided mechanically prethinned, dimpled, and, in the last step, electrolytic thinning of the thin plates until the electron transparency occurred.

2.3. Corrosion Test. Corrosion test was carried out by using the conventional three-electrode cell containing the work electrode, a saturated calomel electrode (SCE) as the reference electrode, and a platinum sheet as the counter electrode. The electrolyte solution was simulated sea water and its chemical components (wt\%) was shown in Table 2. Prior to the polarization step, the samples were exposed to simulated sea water under open circuit potential for $10 \mathrm{~min}$ (at room temperature about $25^{\circ} \mathrm{C}$ ). After that, a fairly stable potential
TABLE 2: Composition of simulated sea water (wt \%).

\begin{tabular}{lc}
\hline Compound & Concentration $(\mathrm{g} / \mathrm{L})$ \\
\hline $\mathrm{NaCl}$ & 24.53 \\
$\mathrm{MgCl}_{2}$ & 5.20 \\
$\mathrm{Na}_{2} \mathrm{SO}_{4}$ & 4.09 \\
$\mathrm{CaCl}_{2}$ & 1.16 \\
$\mathrm{KCl}$ & 0.695 \\
$\mathrm{NaHCO}$ & 0.201 \\
$\mathrm{KBr}_{3}$ & 0.101 \\
$\mathrm{H}_{3} \mathrm{BO}_{3}$ & 0.027 \\
$\mathrm{SrCl}_{2}$ & 0.025 \\
$\mathrm{NaF}$ & 0.003
\end{tabular}

could be achieved, and then the potentiodynamic polarization was carried out at a scan rate of $0.333 \mathrm{mV} / \mathrm{s}$. The size of effective testing area exposed to simulated sea water was $10 \mathrm{~mm} \times 10 \mathrm{~mm}$ with another nonworking surface covered with epoxy resin.

\section{Results and Discussion}

3.1. Microstructural Modifications Induced by HCPEB Irradiation. Figure 2 gives Metallographic surface morphologies of the treated samples. In most material for which HCPEB irradiation has been applied, typical cratering is usually observed. This is also the case for superalloy GH4169. Seen from Figure 2(a), a fairly high density of craters was formed due to the HCPEB irradiation. Actually, the craters are the typical feature of many HCPEB irradiated metal surfaces, which have been observed by many researchers $[13,14]$. It is well established that the craters formed at the metal surface are the result of local sublayer melting and eruptions, occurring preferentially at inclusions [3]. With the increment of pulses the number density of the craters decreased, seen visibly in Figures 2(b) and 2(c). Figure 2(d) taken from Figures 2(a)-2(c) gives the density of the craters more clearly. This change was due to the melting and dissolution of the inclusions under increasing number of pulses, and the craters formed previously were fused or removed by the subsequent bombardment. Based on this conclusion, some researchers believed that crater eruption events can contribute to the selective surface purification effect $[3,15]$. Besides, the composition of the surface can be also homogenized due to the repeated melting.

Figure 3 exhibits the SEM images of the irradiated surface where the craters were seldom present. It can be clearly seen that large numbers of slipping bands with different slip direction were induced by HCPEB irradiation. As we know, dislocation slipping is an important deformation mechanism in faced-centered-cubic (fcc) metals. According to 


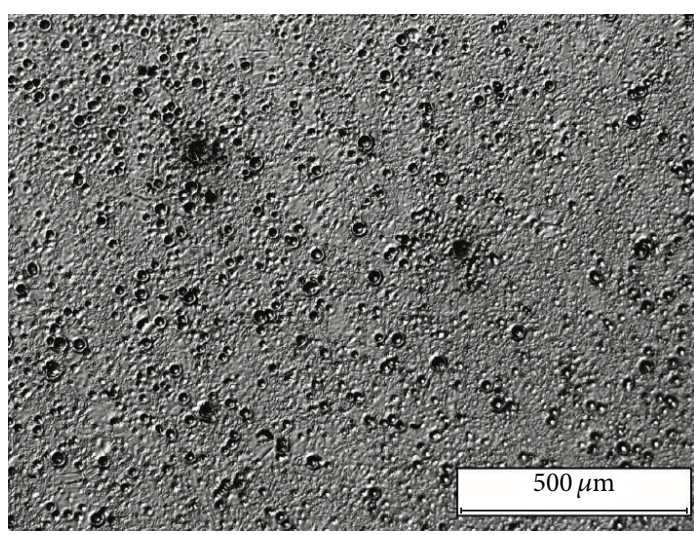

(a)

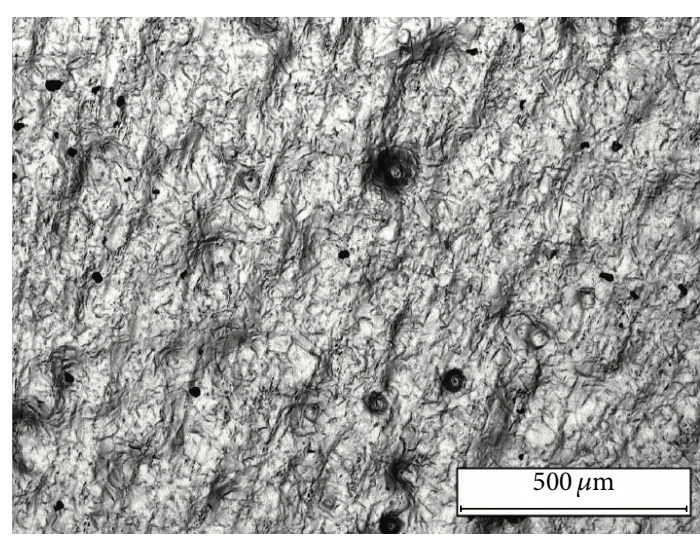

(c)



(b)



(d)

Figure 2: Metallographic images of the samples with different HCPEB pulses (a) 1 pulse, (b) 10 pulses, (c) 20 pulses, and (d) evolution of crater density with the number of pulses.

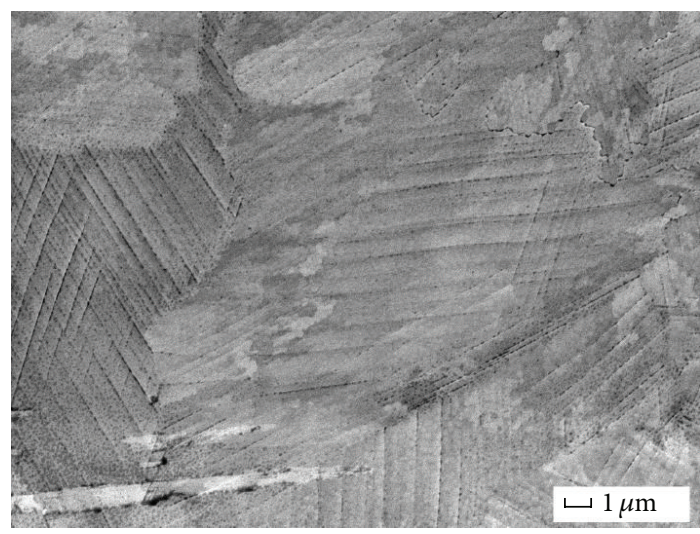

FIGURE 3: SEM micrograph of the sample irradiated by 20-pulsed HCPEB irradiation.

the numerical simulation of the thermal-mechanical process of HCPEB treatment by Zou et al. [16], they suggested that the surface stress in the near surface layer reached
$10^{2}-10^{3}$ of $\mathrm{MPa}$, and the estimated deformation rate reached $10^{4}-10^{5} \mathrm{~s}^{-1}$, which could produce very violent deformation in the surface layer of the irradiated material. Under such high stress and strain rate, multiple slip systems were driven successfully, and, consequently, cross-slip was induced. In addition, nanostructures can be also observed in Figure 3, which were homogeneously dispersed on the irradiated surface.

Figure 4 shows the typical TEM image in the top surface layer of the irradiated sample. It reveals that very fine grains or cells with sizes of 100 150 nm and clear boundaries were present in the surface layer (shown in Figure 4(a)). During the HCPEB irradiation, the concentrated energy flux acting on the metal surface was the first to create a melted layer and craters. Subsequently, depending on the higher energy transferred to the sample, the top surface experienced a complete remelting. After melting, rapid solidification occurred due to the rapid heat extraction towards the bulk $[17,18]$. Under the high speed directional solidification, the planar solidification interface became instable, which made the solidification proceed in a way of cellular crystal. Besides these fine grains 


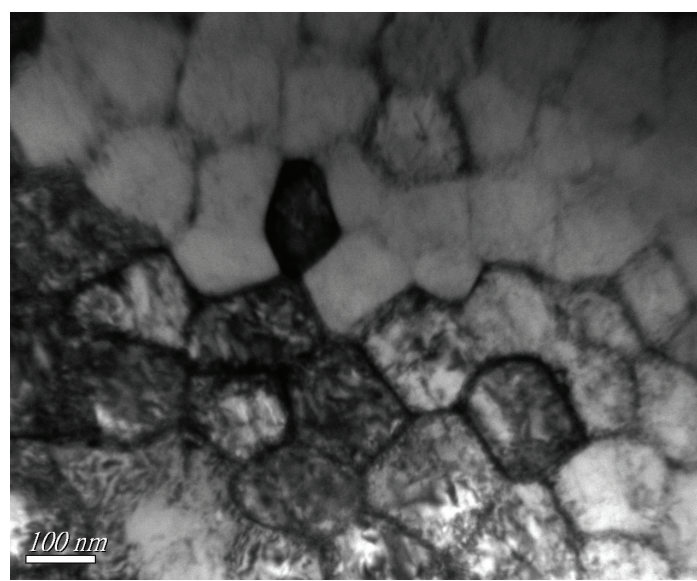

(a)

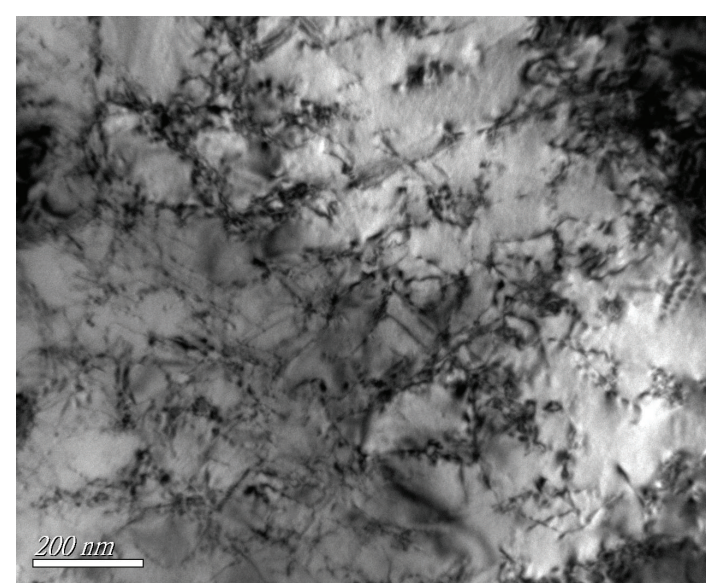

(b)

FIGURE 4: TEM micrographs of the sample irradiated by 20-pulsed HCPEB irradiation.

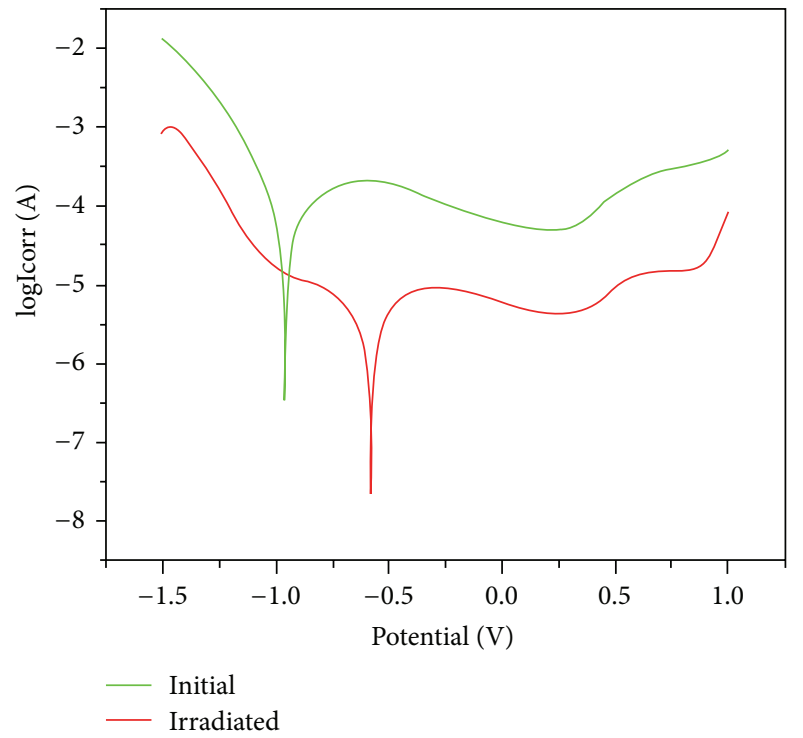

FIgURE 5: Polarization curves of the sample before and after 20pulsed HCPEB irradiation.

or cells, high density of dislocations was also obtained in local regions of the irradiated layer, indicating that severe plastic deformation took place after HCPEB treatment. It is reasonable to expect significant property improvements of the superalloy by HCPEB irradiation due to the formation of both nanostructures and high density of dislocations.

3.2. Corrosion Resistance. The potentiodynamic polarization curves of the initial and irradiated samples measured in simulated sea water are given in Figure 5 and the corresponding corrosion data are listed in Table 3. Clear differences are observed in terms of corrosion resistance. Based on the cathodic part of the polarization curve, the corrosion rate was normally proportional to the calculated corrosion current density. Compared with the initial sample, the corrosion resistance after HCPEB irradiation increased obviously,
TABLE 3: The corrosion data of the initial and irradiated sample.

\begin{tabular}{lcc}
\hline Samples & Ecorr $(\mathrm{mV})$ & Icorr $\left(\mu \mathrm{A} / \mathrm{cm}^{-2}\right)$ \\
\hline Initial & -966 & 42.53 \\
Irradiated & -581 & 2.786 \\
\hline
\end{tabular}

which in particular was reflected by a significant decrease in the corrosion current density (Icorr). As seen in Table 3, after 20 -pulsed irradiation, there was a sharp decrease in the Ecorr value $(-581 \mathrm{mV})$.

We all know, when the material was immerged in the simulated sea water, a passive film could be formed on the top surface. However, due to the inclusions inherent in the initial sample, the passive film was usually not uniform and much weaker at the sides of inclusions. Therefore, pitting corrosion was easy to happen. As for the improved corrosion resistance after HCPEB irradiation, two additional effects on the corrosion behaviours can be called upon. First, as for the 20-pulsed irradiated sample, the number of craters decreased sharply (Figure $2(\mathrm{~d})$ ), which resulted in the elimination of inclusions at the near surface by a selective purification mechanism together with the formation of a homogeneous and smooth protective layer. Therefore, the density of corrosion pitting could be decreased remarkably due to the reduction of sensitive sites. Second, nanoremelting layer and high density of dislocation slips (Figure 4) introduced by $\mathrm{HCPEB}$ irradiation played a dominating role in the formation of the compact and thick passive layer. In the simulated liquid, a large amount of grains boundaries provided by nanostructures and a mass of microstructural defects could supply plenty of path ways and positions for the adsorption and entrance of dissolved $\mathrm{O}^{2-}$ at the onset of corrosion, promoting the formation of the protective passive layer. Therefore, the passive film induced by the 20-pulsed HCPEB treatment offered a good corrosion protection due to the low density of craters, nanostructures, and high destiny of structural defects. 


\section{Conclusions}

(1) After HCPEB irradiation, many craters were inevitably formed on the irradiated surface, and the number density of craters decreased with the increment of HCPEB pulses. The HCPEB technique was revealed as an effective way to realize surface purification of superalloy GH4169.

(2) Significant refinement of microstructures was inducted due to the rapid solidification process. Moreover, high density of dislocation slip occurred as a consequence of intense plastic deformation.

(3) HCPEB irradiation caused a significant improvement of corrosion resistance of the superalloy GH4169. The selective purification effect resulting from the crater erupting, the homogenized composition due to the repeated melting, and nanostructures introduced by HCPEB irradiation played a dominating role in the mechanisms of corrosion resistance.

\section{Conflict of Interests}

The authors declare that there is no conflict of interests regarding the publication of this paper.

\section{Acknowledgments}

This work was supported by the National Natural Science Foundation of China (U1233111), to which the authors are very grateful.

\section{References}

[1] J. X. Zou, T. Grosdidier, K. M. Zhang, and C. Dong, "Mechanisms of nanostructure and metastable phase formations in the surface melted layers of a HCPEB-treated D2 steel," Acta Materialia, vol. 54, no. 20, pp. 5409-5419, 2006.

[2] Y. Qin, C. Dong, Z. F. Song et al., "Deep Modification of materials by thermal stress wave generated by irradiation of high-current pulsed electron beams," Journal of Vacuum Science and Technology A: Vacuum, Surfaces and Films, vol. 27, no. 3, pp. 430-435, 2009.

[3] K. M. Zhang, J. X. Zou, T. Grosdidier, C. Dong, and D. Z. Yang, "Improved pitting corrosion resistance of AISI 316L stainless steel treated by high current pulsed electron beam," Surface and Coatings Technology, vol. 201, no. 3-4, pp. 1393-1400, 2006.

[4] C. Dong, A. M. Wu, S. Z. Hao et al., "Surface treatment by high current pulsed electron beam," Surface and Coatings Technology, vol. 163-164, pp. 620-624, 2003.

[5] J. Cai, S. Z. Yang, L. Ji, Q. F. Guan, Z. P. Wang, and Z. Y. Han, "Surface microstructure and high temperature oxidation resistance of thermal sprayed CoCrAlY coating irradiated by high current pulsed electron beam," Surface and Coatings Technology, vol. 251, pp. 217-225, 2014.

[6] Q. F. Guan, X. T. Wang, J. Zhu et al., "Fabrication of micropore on AISI 304L austenitic stainless steel surface by high-current pulsed electron beams irradiation," ISIJ International, vol. 49, no. 9, pp. 1449-1451, 2009.
[7] R. Damodaram, S. G. S. Raman, D. V. V. Satyanarayana, G. M. Reddy, and K. P. Rao, "Hot tensile and stress rupture behavior of friction welded alloy 718 in different pre-and post-weld heat treatment conditions," Materials Science and Engineering: A, vol. 612, pp. 414-422, 2014.

[8] J. J. Debarbadillo and S. K. Mannan, "Alloy 718 for oilfield applications," JOM, vol. 64, no. 2, pp. 265-270, 2012.

[9] T. Chen, J. Nutter, J. Hawk, and X. B. Liu, "Corrosion fatigue crack growth behavior of oil-grade nickel-base alloy 718. Part 1: effect of corrosive environment," Corrosion Science, vol. 89, pp. 146-153, 2014.

[10] M. C. Li, S. Z. Hao, H. Wen, and R. F. Huang, "Surface composite nanostructures of AZ91 magnesium alloy induced by high current pulsed electron beam treatment," Applied Surface Science, vol. 303, pp. 350-353, 2014.

[11] Y. Xu, Y. Zhang, S. Z. Hao et al., "Surface microstructure and mechanical property of WC-6\% Co hard alloy irradiated by high current pulsed electron beam," Applied Surface Science, vol. 279, pp. 137-141, 2013.

[12] K. M. Zhang and J. X. Zou, "Formation of ultrafine twinned austenite on a cold rolled 316L stainless steel induced by pulsed electron beam treatment under heating mode," Thin Solid Films, vol. 526, pp. 28-33, 2012.

[13] K. Zhang, J. Zou, T. Grosdidier, and C. Dong, "Formation and evolution of craters in carbon steels during low-energy highcurrent pulsed electron-beam treatment," Journal of Vacuum Science and Technology A: Vacuum, Surfaces and Films, vol. 27, no. 5, pp. 1217-1226, 2009.

[14] Y. Qin, C. Dong, X. A. Wang et al., “Temperature profile and crater formation induced in high-current pulsed electron beam processing," Journal of Vacuum Science and Technology A, vol. 21, no. 6, pp. 1934-1938, 2003.

[15] J. X. Zou, K. M. Zhang, S. Z. Hao, C. Dong, and T. Grosdidier, "Mechanisms of hardening, wear and corrosion improvement of $316 \mathrm{~L}$ stainless steel by low energy high current pulsed electron beam surface treatment," Thin Solid Films, vol. 519, no. 4, pp. 1404-1415, 2010.

[16] J. X. Zou, Y. Qin, C. Dong, X. G. Wang, A. M. Wu, and S. Z. Hao, "Numerical simulation of the thermal-mechanical process of high current pulsed electron beam treatment," Journal of Vacuum Science and Technology A: Vacuum, Surfaces and Films, vol. 22, no. 3, pp. 545-552, 2004.

[17] J. Zou, K. Zhang, T. Grosdidier, and C. Dong, "Analysis of the evaporation and re-condensation processes induced by pulsed beam treatments," International Journal of Heat and Mass Transfer, vol. 64, pp. 1172-1182, 2013.

[18] K. M. Zhang, J. X. Zou, B. Bolle, and T. Grosdidier, "Evolution of residual stress states in surface layers of an AISI D2 steel treated by low energy high current pulsed electron beam," Vacuum, vol. 87, pp. 60-68, 2013. 

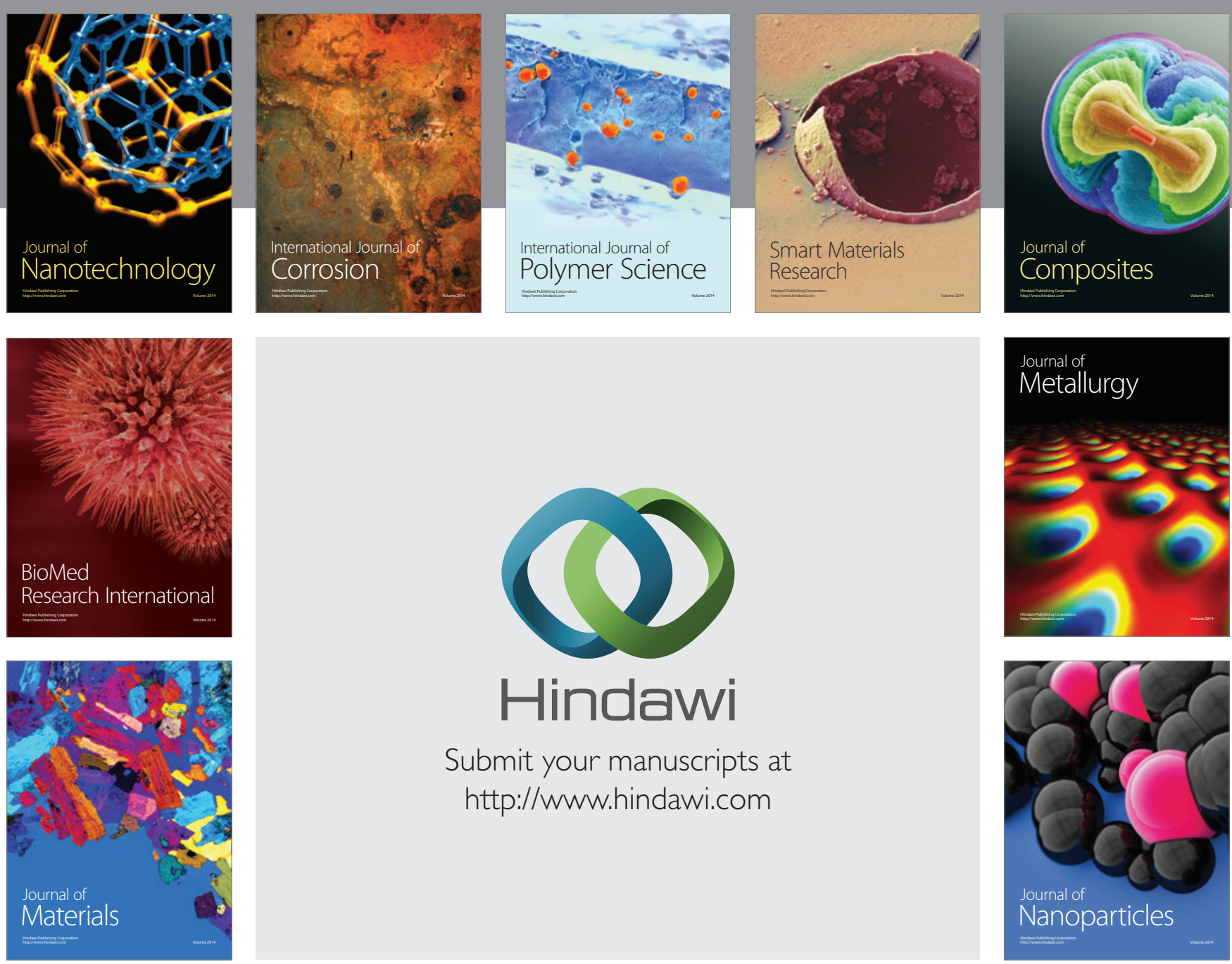

Submit your manuscripts at http://www.hindawi.com
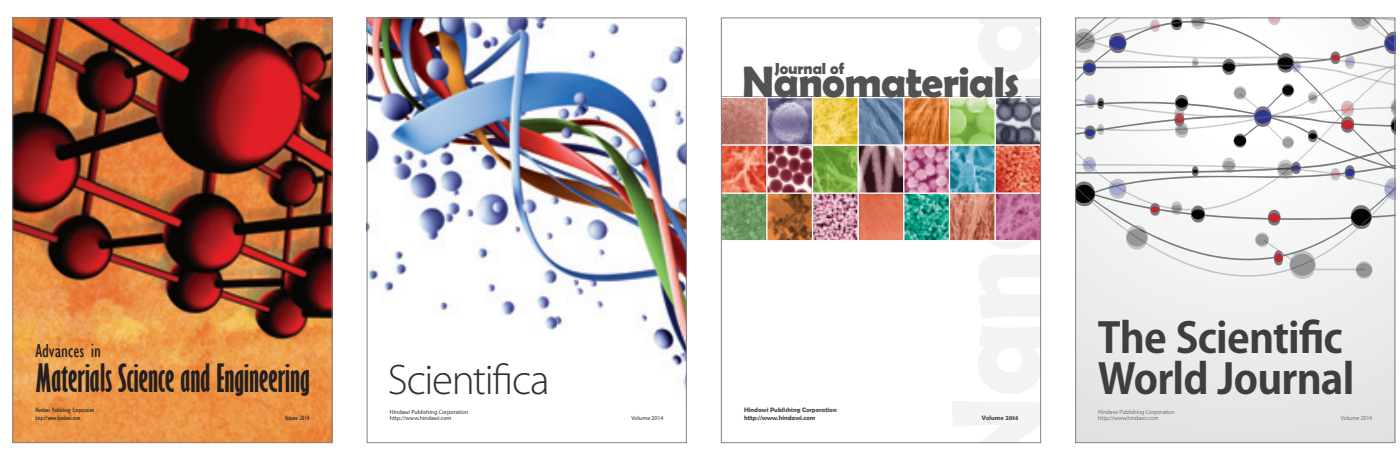

\section{The Scientific World Journal}
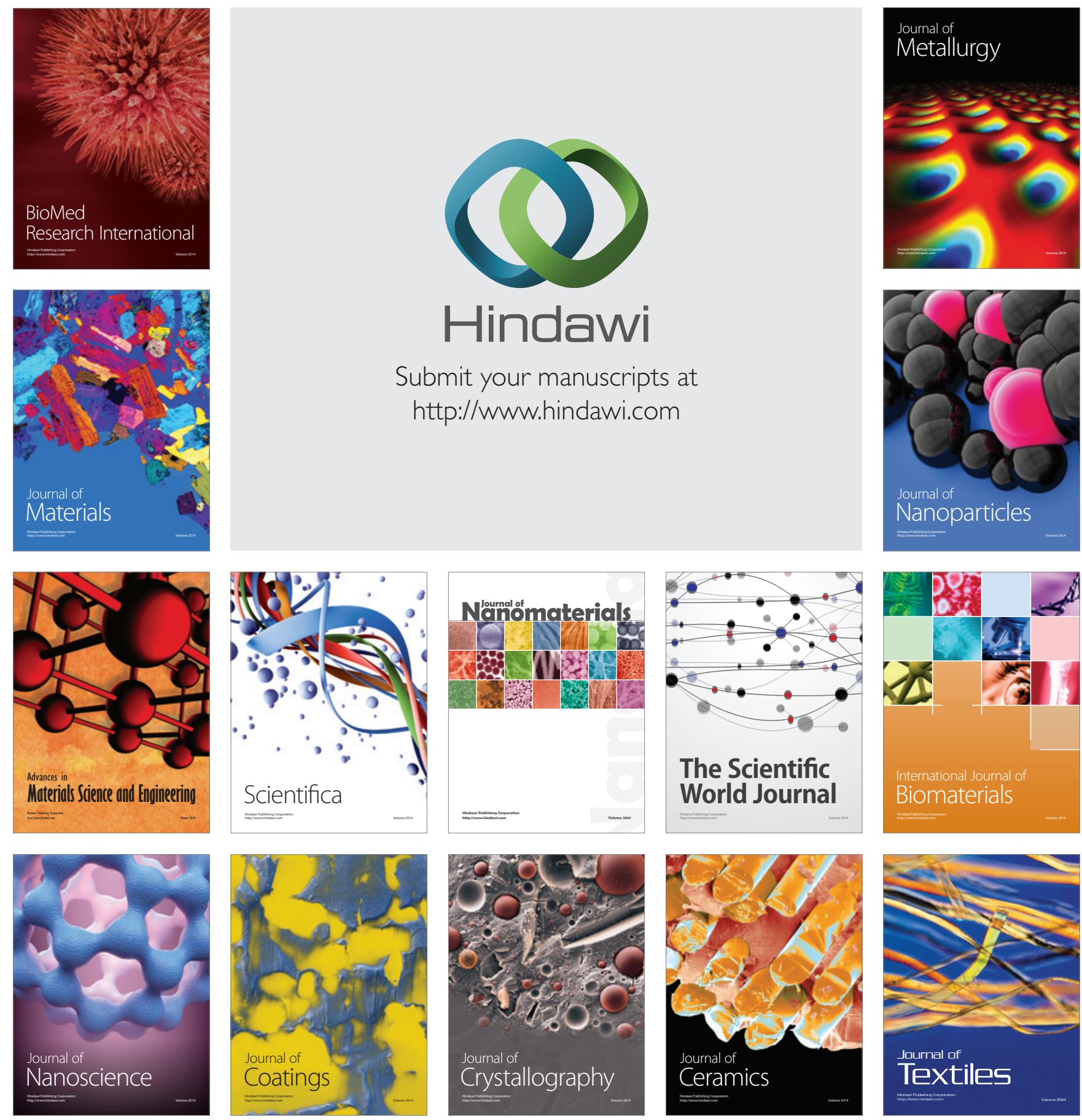